\title{
Sustainable adsorbents formed from by-product of acid activation of vermiculite and leached-vermiculite-LDH hybrids for removal of industrial dyes and metal cations
}

\author{
Wojciech Stawiński \\ Agnieszka Węgrzyn \\ Grzegorz Mordarski \\ Michał Skiba \\ Olga Freitas \\ Sónia Figueiredo
}

\section{Abstract}

Hydrotalcite-like layered double hydroxide (LDH) materials were synthesized from liquid waste by-product produced during acid activation of vermiculite (raw (W) and expanded (Ve)), and by combining the waste with the activated mineral, novel hybrid vermiculitehydrotalcite-like materials were obtained in one-pot synthesis. Batch system adsorption experiments were performed on fresh and calcined (at $450^{\circ} \mathrm{C}$ ) materials using two anionic dyes (Congo Red - CR, and Reactive Red 184 - R), a cationic dye (Astrazon Red - AR), and $\mathrm{Cu} 2+$. Calcination significantly increased the materials' adsorption capacities for all the pollutants. The highest adsorption capacities of the LDH derived from $W$ were $289 \pm 2,137 \pm 2,38.2 \pm 0.6$ and $64 \pm 2 \mathrm{mgg}-1$, while for the ones derived from Ve were $214 \pm 2$, $119.5 \pm 0.3,35.9 \pm 0.7$ and $66 \pm 3 \mathrm{mg} \mathrm{g}-1$ for $\mathrm{CR}, \mathrm{R}, \mathrm{AR}$ and $\mathrm{Cu} 2+$, respectively. The hybrids obtained from $\mathrm{W}$ attained removal levels of $238 \pm 3,111 \pm 2,44 \pm 1$ and $70 \pm 1 \mathrm{mg} \mathrm{g}-1$ and their counterparts derived from Ve reached $84 \pm 1,34.1 \pm 0.5,43 \pm 2$ and $75 \pm 1 \mathrm{mg} \mathrm{g}-1$ for $\mathrm{CR}, \mathrm{R}, \mathrm{AR}$ and $\mathrm{Cu2+}$, respectively. Strong synergic effect on adsorption was observed in the hybrid materials, especially in these derived from Ve. These adsorbents had higher (up to 400\%) adsorption capacities than theoretical ones prepared by mixing ex-situ appropriate amounts of activated vermiculite and LDH. All the materials were characterized by XRD, SEM-EDS, and ATR techniques. The proposed procedure is a sustainable approach to clay minerals valorization and my open new possibilities in fields such as wastewater treatment or catalysis.

\section{Keywords}

AdsorptionModified claysVermiculiteHydrotalciteHybrid adsorbents

\section{Introduction}

Decreasing the environmental impact of wastewaters to acceptable levels has become the first and major modern world's concern and the demand on technologies for pollutants removal has been rising (Sevekow, 2003; Pereira and Alves, 2011).

Dyes are common pollutants generated in various industries (Rozada et al., 2003; Angın et al., 2013) and are often accompanied by heavy metals in wastewaters (Pereira and Alves, 2011). Both pollutants pose a hazard to living organism and are resistant to conventional treatment methods (Forgacs et al., 2004; Bhatnagar and Jain, 2005). Adsorption is considered one of the best industrial wastewaters treatment methods due to its efficiency (even for low contaminant concentrations), broad applicability, ease of operation, and insensibility to toxicants (Leitão and Serrão, 2005; Ali et al., 2012). The desired adsorbent should be derived from easily available, inexpensive, non-hazardous and feasible to recycle materials (Ali et al., 2012; Ummartyotin and Pechyen, 2016). Different adsorbents such as activated carbon (Ayranci and Duman, 2009, Ayranci and Duman, 2010; Duman and Ayranci, 2010), sepiolite (Duman et al., 2015a), vermiculite (Duman et al., 2015b) and magnetic carbon nanotubes (Duman et al., 2016) have been used successfully for the treatment of wastewaters including dyes and metal ions. On the other hand, researches have been continued for inexpensive alternative adsorbents having reasonable adsorption efficiencies (Duman et al., 2015b).

Layered materials such as clay minerals and layered double hydroxides (LDH) are promising in the field of adsorption (Pinnavaia, 2004; Roy et al., 2006). The first are minerals with a structure built of layers that may carry a negative charge balanced by a cation localized between the layers. The second, have similar layered structure, however the sheets have a positive charge balanced by an interlayer anion (Braterman et al., 2004). These charge balancing ions can be replaced giving the materials good cation and anion exchange properties, respectively. 
These materials can be subjected to modifications in order to change their properties (Bergaya and Lagaly, 2006; Komadel and Madejova, 2006; Lagaly et al., 2006; Stawiński et al., 2016; Stawiński et al., 2017a; Stawiński et al., 2017b; Stawiński et al., 2017c). One of the most common modifications of clay minerals, among thermal and surfactant treatments, is their acid activation resulting in increased maximum adsorption capacity (Komadel and Madejova, 2006; Duman and Tunç, 2008; Chmielarz et al., 2012; Stawiński et al., 2016; Stawiński et al., 2017c). However, that process might be considered as unsustainable because it usually produces highly acidic waste containing metals leached during the procedure. It was previously reported by Węgrzyn et al. (2018) that the procedure's environmental impact of may be diminished by applying fine wet milling of the clay mineral as a pretreatment step decreasing the acid concentration necessary to obtain desired adsorption capacity.

This study aimed to make the acid activation more sustainable by finding application of the waste produced during the procedure. The waste was successfully used to produce a layered hydrotalcite-like material characterized by good adsorption properties for anions (anionic dyes) and cations (metal) removal. Moreover, by using the waste and the acid treated clay a hybrid vermiculite-hydrotalcite material, capable of adsorbing metal ions and both anionic and cationic dyes, was prepared. Such adsorbents were subjected to thermal modification that increased their adsorption capacity for all aforementioned pollutants. To the authors' best knowledge such procedure and its application have not been reported in the literature so far. This work contributes to the search of solutions to decrease the environment impact of clay minerals acid activation and gives solution to remediation of waste waters leaden with cationic and anionic pollutants by means of versatile adsorbents obtained in simple one-pot synthesis.

\section{Materials and methods}

\subsection{Materials}

\subsubsection{Adsorbates}

The cationic dye Astrazon Red FBL 200\% (AR), (CAS 12221-69-1), and two anionic dyes, Reactive Red 184 (R) (CAS 85496-37-3) and Congo Red (CR) (CAS 573-58-0), supplied by Dystar were used for the adsorption experiments. Analytical grade salt $\mathrm{CuCl} 2 \cdot 2 \mathrm{H} 2 \mathrm{O}$, employed for preparation of $\mathrm{Cu} 2+$ solutions, (NH4)2CO3 and $\mathrm{Na} 2 \mathrm{CO} 3$ were obtained from Sigma-Aldrich. Raw (W) and expanded (Ve) vermiculites were kindly supplied by ROMINCO POLSKA Sp. z o.o. The dyes' structures are presented in the Supporting Materials in Fig.S1.

\subsubsection{Adsorbents}

\subsubsection{Nomenclature}

The first sample name's part stands for the material used in the synthesis (W and Ve, for raw and expanded vermiculite, respectively). The second part indicates the fraction obtained during the acid treatment of the starting materials, later used in the synthesis $(L-$ only liquid; LS - liquid and solid, hybrid samples; S - only solid residual fraction-acid leached vermiculite). The next part indicates nitric acid concentration (M) used during the synthesis, and the last part, if present, denotes calcination at $450{ }^{\circ} \mathrm{C}$.

\subsubsection{Samples preparation}

\subsubsection{Adsorbents prepared from solid faction (S)}

Volume of $100 \mathrm{~mL}$ of $1.8 \mathrm{M} \mathrm{HNO} 3$ was heated to $98^{\circ} \mathrm{C}$ in a round bottom reactor equipped with a condenser. Then a $10 \mathrm{~g}$ portion of raw vermiculite (W) was added to it and stirred (400 r.p.m) for $2 \mathrm{~h}$ at constant temperature. The sample was centrifuged (10 min at 4500 r.p.m.) and the supernatant was collected. The sediment was washed in 5 cycles of mixing with distilled water and centrifugation (10 min at 4500 r.p.m. in each cycle), and dried at $40^{\circ} \mathrm{C}$ overnight in order to obtain sample W-S-1.8. Similar procedure was applied using $\mathrm{W}$ and 3.2 M HNO3 to produce sample W-S-3.2, and using Ve to obtain samples Ve-S-1.8 and Ve-S-3.2. 
The supernatant obtained after acid leaching of vermiculite (section above) was alkalinized with ammonium carbonate ( $\mathrm{pH}$ about 6$)$ and added dropwise to another reactor containing $0.1 \mathrm{M} \mathrm{Na} 2 \mathrm{CO} 3$,. The $\mathrm{pH}$ was raised to $10.0 \pm 0.2$, the content was heated to $60{ }^{\circ} \mathrm{C}$ and left under constant stirring (400 r.p.m.) for 24 h. Then the material was centrifuged (10 min at 4500 r.p.m.), washed 5 times as described above, left to dry overnight at $40^{\circ} \mathrm{C}$ and ground in a mortar in order to produce sample W-L-1.8. Similar procedure was applied using 3.2 M HNO3 to obtain sample W-L-3.2 and to the expanded vermiculite for samples Ve-L-1.8 and Ve-L-3.2. The reference hydrotalcite (HT-REF), with the formula [Mg0.667 Al0.235 Fe0.098 (OH)2] (CO3)0.167 $0.5 \mathrm{H} 2 \mathrm{O}$, was prepared by co-precipitation method to simulate cationic composition of the starting vermiculite (W), which was previously reported in Stawiński et al. (2016), assuming that maximum molar fraction of trivalent cations within LDH structure is used.

\subsubsection{Hybrid adsorbents (LS)}

The hybrid adsorbents were formed according to the procedure described in the previous section however both liquid and solid fractions of the acid activated vermiculites, without separation, were used in the synthesis of samples W-LS-1.8, W-LS-3.2, Ve-LS-1.2 and VeLS-3.2.

\subsection{Methods}

\subsubsection{Characterization of materials}

X-ray fluorescence (XRF) analysis was performed using Skayray Instrument EDX $3600 \mathrm{H}$ - Alloy Analyser. The materials' structure was studied with X-ray powder diffractometer (Bruker, D2 Phaser) equipped with CuKa radiation source $(\lambda=0.154184 \mathrm{~nm}$; measurement range $2-70^{\circ} 2 \theta$; step size $0.02^{\circ} 2 \theta$; slit width $0.6 \mathrm{~mm}$; step scan size $0.02^{\circ}$; counting time $1 \mathrm{~s}$ ). A field emission scanning electron microscope (FESEM) Hitachi S-4700 equipped with a Vantage Noran EDS system was used to record the SEM micrographs and to analyze elements distribution in the materials. The samples' surface were prepared by carbon coating. The Infrared spectra (ATR-FTIR) were recorded using Attenuated Total Reflectance technique with diamond crystal, in the range of $525-4000 \mathrm{~cm}-1 \mathrm{with} 2 \mathrm{~cm}-1 \mathrm{resolution}$ and 50 scans (Nicolet 6700 FT-IR, DTGS detector, Thermo Scientific). Second derivative method was used in the case of ATR-FTIR analyses for better peaks detection.

\subsubsection{Adsorption experiments}

Weighted portions of $20 \mathrm{mg}$ of each material were placed in Erlenmeyer's flasks and mixed with $40 \mathrm{~mL}$ of solutions with concentrations equal $200 \mathrm{mg} \mathrm{L}-1$ for the dyes (AR, R, CR) and $30 \mathrm{mg} \mathrm{L}-1$ for Cu2+. The flasks were closed and stirred (400 r.p.m.) for $2 \mathrm{~h}$ at room temperature $\left(24^{\circ} \mathrm{C}\right)$ without $\mathrm{pH}$ adjustment. Each experiment was made in triplicate. Then the samples were centrifuged $(5 \mathrm{~min}$ at 4500 r.p.m.) and the adsorbates concentration in the supernatant determined. The dyestuffs concentrations were measured using UVVis spectrophotometer (Thermo Scientific, Evolution 300). Concentration of Cu2+ was determined by atomic absorption spectroscopy (Analytik Jena High-Resolution Continuum Source Atomic Absorption Spectrometer, ContrAA 700).

The adsorption capacity was calculated according to Eq.1:

$$
q=\frac{\left(C_{0}-C_{e q}\right) V}{m}
$$

where $\mathrm{q}$ is adsorption capacity (mg g-1), C0 and Ceq initial and final concentration $(\mathrm{mg} L-1)$ respectively, $V$, adsorbate volume $(\mathrm{L})$ and $\mathrm{m}$, adsorbent mass $(\mathrm{g})$.

\section{Results and discussion}

\subsection{Characterization of materials}

3.1.1. Chemical composition of the adsorbents and relation with synthesis yield

The reaction's yield when the solid fraction of Ve was used was higher than for W due to higher resistance of the first material to acid attack. The yield lower than $100 \%$ may be due to removal of impurities from the starting materials that were not incorporated in the 
products, and to incomplete precipitation during the synthesis. Additional substrates not present in the starting materials (e.g. CO32- or NO3-) might have been incorporated into the products rendering the yield higher than $100 \%$ in the case of the hybrids obtained from $\mathrm{W}$ in $3.2 \mathrm{M}$ acid (Fig. 1). The share of $\mathrm{LDH}$ and vermiculite phase in the hybrid material (Fig. 1) was calculated according to the XRF analysis and mass loss in calcination (results not shown).

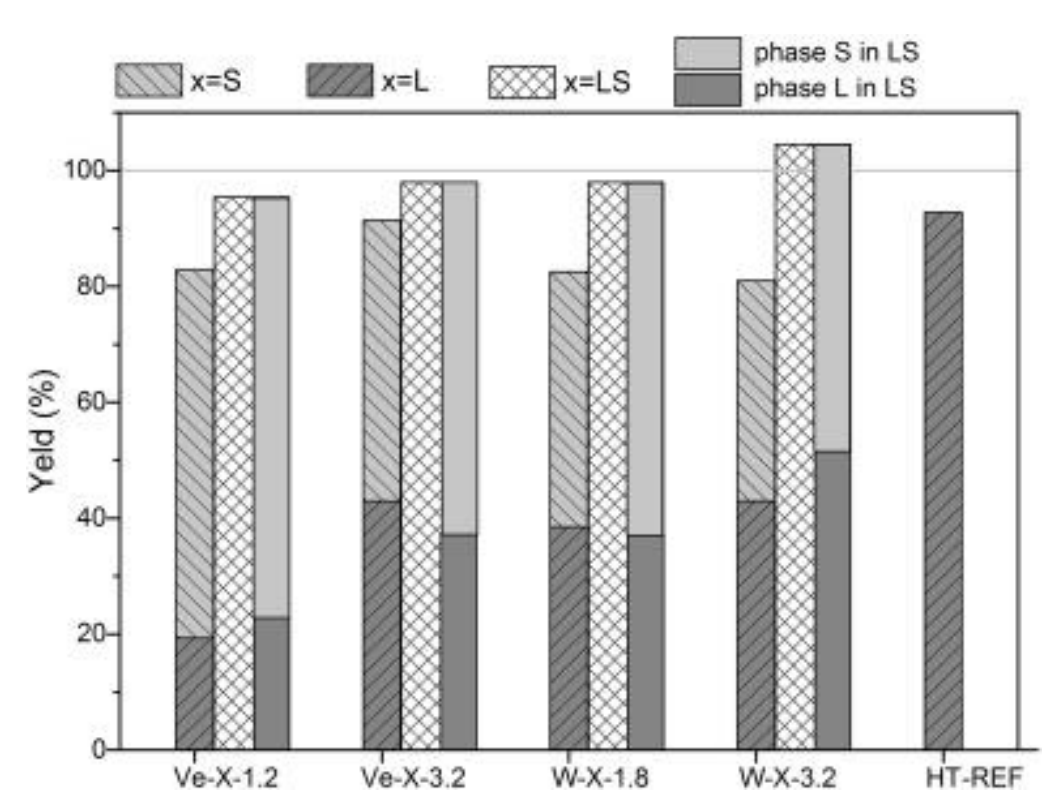

Fig. 1. Synthesis efficiency and phase composition of the hybrid hydrotalcite-vermiculite samples.

The elements distribution was quantified in the samples obtained from raw vermiculite (W) treated in 3.2 M HNO3 (Fig. 2). The S-sample showed high concentration of $\mathrm{Si} 4+$ in amorphous silica formed during the treatment, and small amounts of $\mathrm{Mg} 2+, \mathrm{Al} 3+$ and $\mathrm{Fe} 3+/ \mathrm{Fe} 2+$ due to incomplete dissolution of the material. The L-sample had uniform distribution of $\mathrm{Al} 3+$, Mg2+ and Fe3+/Fe2+, constituting its main components, and some Si4+ leached from the starting material built in the structure. The hybrid adsorbent (LS) contained Si4+, Al3+ and $\mathrm{Mg} 2+$ with homogeneous distribution however, $\mathrm{Mg} 2+$ and $\mathrm{Al} 3+$ accumulated in some regions (regions marked as $\mathrm{HT}$, Fig. 2) where the signal from Si4+ was weaker, what confirms that the amorphous leached material is "obscured" by Mg2+ and Al3+ hydroxides, most probably LDH aggregates (according to XRD analyses).

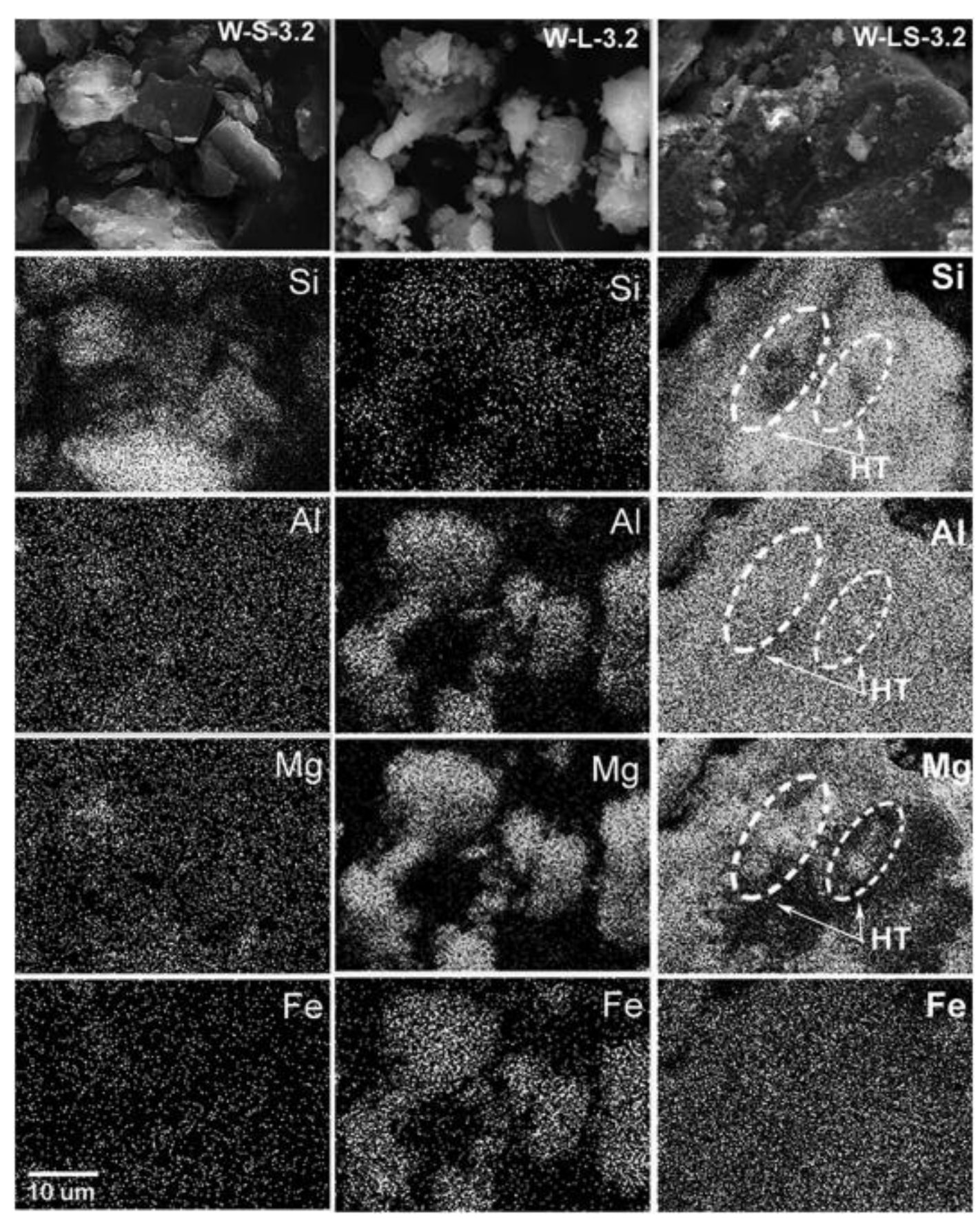

Fig. 2. SEM images and elemental mapping of the sample W-LS-3.2. 
The starting vermiculites had similar chemical composition (XRF analyses, Fig. 3), with Si4+, Al3+, Mg2+, Fe3+ being the dominant components, however Ve contained more $\mathrm{K}+$ and $\mathrm{Ca} 2+$ than $\mathrm{W}$. Acid treatment leached all the cations, except Si4+, with intensity proportional to the used concentration. Ve was more resistant to acid dissolution and some $\mathrm{Al} 3+$ and $\mathrm{K}+$, unlike in its $\mathrm{W}$ counterpart, were still detected in the sample after treatment with 3.2 $\mathrm{M}$ HNO3. The composition of the L-samples was similar to the reference hydrotalcite (HT-REF) however, both adsorbents derived from W and Ve-L-3.2 contained varying content of Fe and some amounts of $\mathrm{Ca} 2+$ and $\mathrm{K}+$ in their structure. Moreover, the sample Ve-L-1.2 had higher amount of Ca2+ and Si4+.

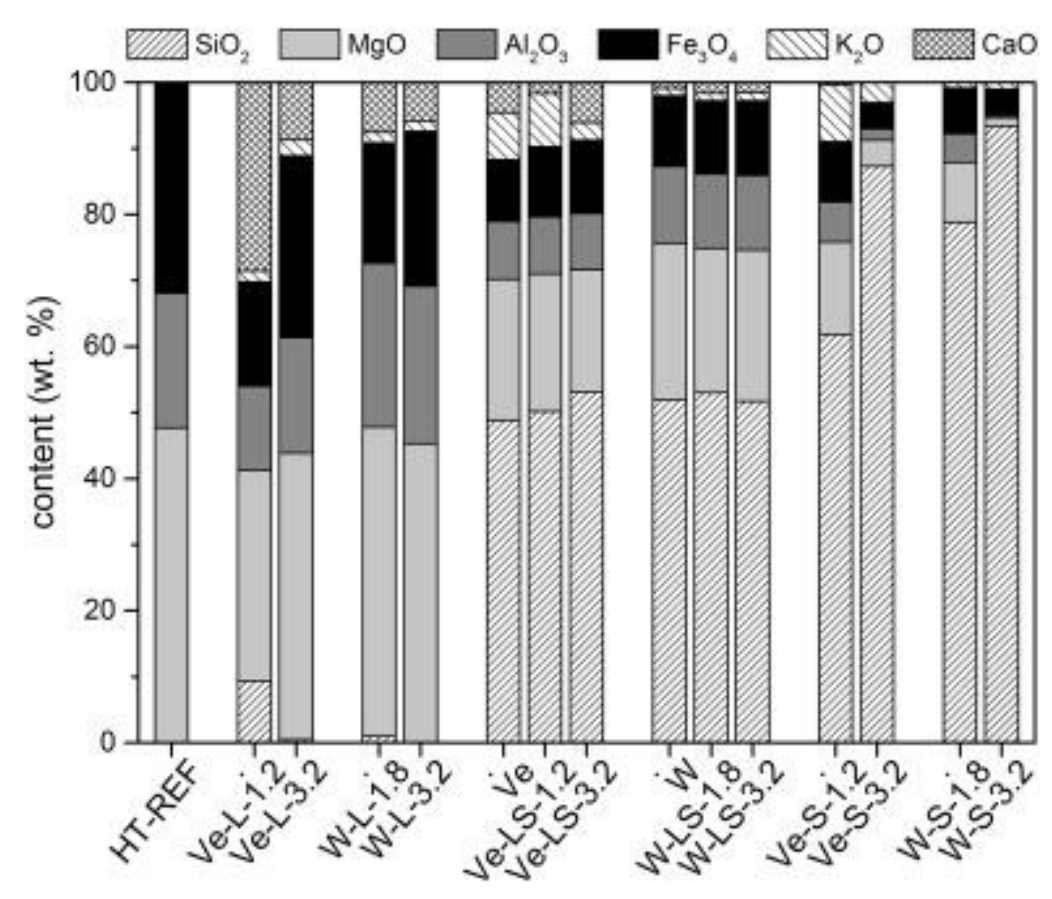

Fig. 3. XRF analysis of the adsorbents' chemical composition.

\subsubsection{XRD analysis}

The XRD patterns of the reference hydrotalcite showed typical reflections at $11.71^{\circ}(d=7.55 \AA, 003), 23.31^{\circ}(d=3.82 \AA, 006), 34.8^{\circ}$ $(d=2.57 \AA, 009+0012), 39.40^{\circ}(d=2.29 \AA, 015), 47.00^{\circ}(d=1.93 \AA, 018), 60.90^{\circ}(d=1.52 \AA, 110)$ and $62.19^{\circ}(d=1.49 \AA, 112)(\operatorname{Roy}$ et al., 2006). Those reflections were present in the L-samples' diffractograms, proving the successful formation of layered double hydroxides. The samples derived from W were more crystalline (lower FWHM of the basal reflection 003) than the ones obtained from Ve. Moreover, a series of other sharp reflections, that may be ascribed to some impurities (e.g. calcium-containing species), were present in the diffractograms (Fig. 4A).
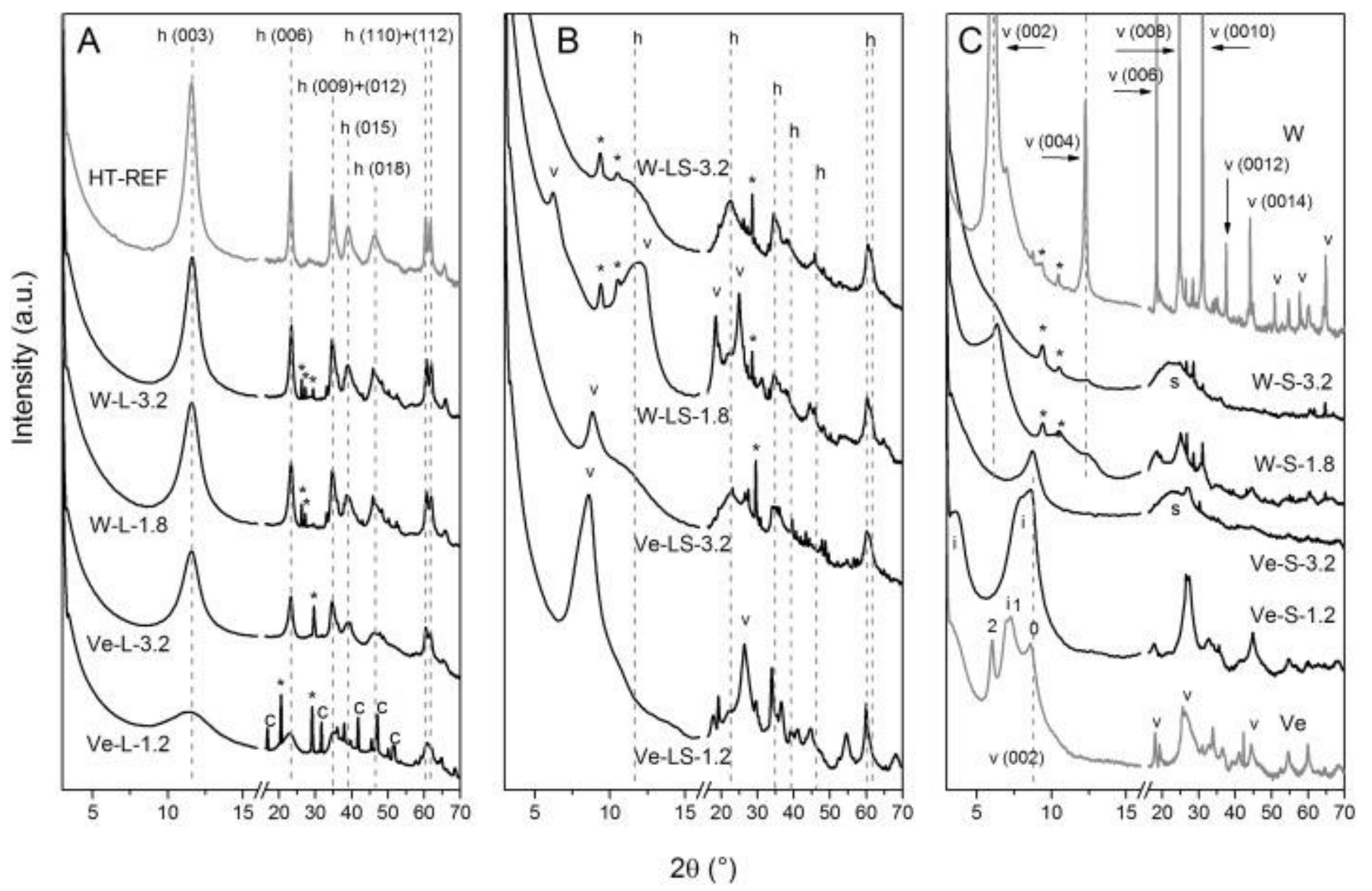

Fig. 4. Phase composition of the materials obtained from the liquid (A), liquid and solid (B), and solid phase after the treatment of vermiculites $(C)\left(v-\right.$ vermiculite, $h$ - hydrotalcite, $c-C a$ containing phases, $s$ - silica, ${ }^{*}$ - other impurities). 

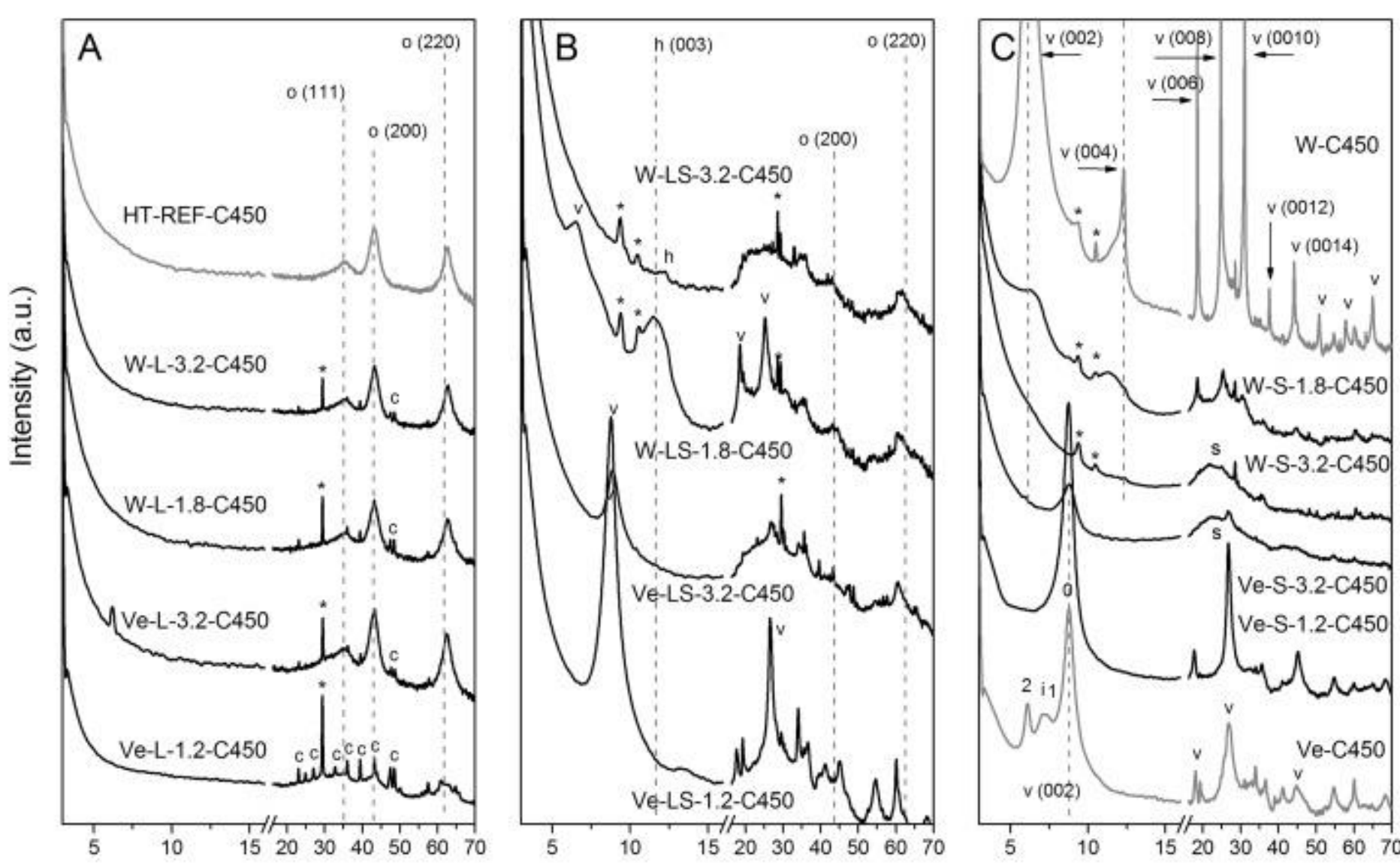

$2 \theta\left({ }^{\circ}\right)$

Fig. 5. Phase composition of the calcined materials obtained from the liquid (A), liquid and solid (B), and solid phase after the treatment of vermiculites $(C)$, ( $\mathrm{o}$ - metal oxide, $v$ - vermiculite, $\mathrm{h}$ - hydrotalcite, $\mathrm{c}-\mathrm{Ca}$ containing phases, $\mathrm{s}-\mathrm{silica},{ }^{*}-\mathrm{other}$ impurities).

Both starting vermiculites showed their reflection at $6.2^{\circ}(d=14.2 \AA, 002), 12.3^{\circ}(d=7.2 \AA, 004), 18.5^{\circ}(d=4.8 \AA, 006), 24.8^{\circ}(d=3.6 \AA$, $008), 31.2^{\circ}(d=2.9 \AA, 0010), 37.5^{\circ}(d=2.4 \AA, 0012), 44.1^{\circ}(d=2.05 \AA, 0014)$ in the case of $W$ and additional two at $7.19^{\circ}(d=1.23 \mathrm{~nm})$ and $8.60^{\circ}(\mathrm{d}=1.03 \mathrm{~nm})$ in the case of $\mathrm{Ve}(\mathrm{Fig} .4 \mathrm{C})$. The patterns for the S-samples were typical of vermiculite subjected to acid treatment (i.e. decreased crystallinity, amorphous silica phase, decreased basal reflections (Forgacs et al., 2004)) (Fig. 4C). Annealing did not result in significant changes in their structure, however the 003 reflection in W-LS-1.8 was less intense (Fig. 5C).

The characteristic reflections of vermiculite and hydrotalcite phase were identified in the hybrid materials' (LS) patterns. The hydrotalcite 003 basal reflection was partially overlapped with the 004 reflection of vermiculite resulting in a broad asymmetric reflection in the samples derived from $\mathrm{W}$. The hydrotalcite reflections located at higher angles were sharper but also asymmetric. The LDH crystallized on the degraded vermiculite's surface had lower crystallinity than the pure hydrotalcite, however the LDH pattern was kept and visible in the diffractograms. That phase's crystallinity depended on the starting vermiculite and acid concentration used in the synthesis (Fig. 4B). It was impossible to identify the 111 reflection of mixed oxide after calcination, however the 200 and 220 reflections were present in the patterns. Moreover, the hydrotalcite phase was still present in the samples derived from W. In the case of W-LS-1.8-C450 the 003 reflection was located at the same position, but in W-LS-3.2-C450 it was shifted towards higher angles which corresponds to intermediate dehydrated layered phase formation (Fig. 5B). This could suggest that, in that particular combination of phases, hydrotalcite exhibited better thermal stability.

The interlayer space and the distance between two metal cations have increased in the hybrid adsorbents compared to the hydrotalcite materials (higher $\mathrm{c}$ and a cell parameters) (Table S3., Supporting Information). It was reported that the a cell parameter increases both with the x parameter and with substitution with Fe3+ (Hansen et al., 1995; Rozov et al., 2010). Additionally the influence of ex-vermiculite support may influence it as well. In the hybrids obtained from $\mathrm{W}$, the hydrotalcite particles' crystal size decreased after the synthesis in 3.2 $\mathrm{M}$ acid compared to the material obtained in the lower concentration, but the latter one (W-LS-1.8-C450) retained layered organization in the vermiculite part, while the first one's structure was disordered (W-LS-3.2-C450). Therefore, the organized LDH structure's growth might have been enhanced in confined spaces of the partially leached vermiculite, while on the porous silica support (W-LS-3.2) crystals form flower-like structures. However, the presence of the acid treatment solid residue, as well as leached cations that are incompatible with the hydrotalcite structure, inhibited the increase of the crystal size. 


\subsubsection{ATR analysis}

The materials' spectra are shown in Fig. 6; the bands list and their assignment are presented in Table S2 in the Supporting Information. Each sample exhibited a band assigned to the vibrations of inner OH groups at around $3620 \mathrm{~cm}-1$ (Somasundaran, 2006). The band associated with $\mathrm{OH}$ stretching vibrations in weakly bonded water molecules (Chmielarz et al., 2012) was present in the spectrum of $\mathrm{W}$ at $3340 \mathrm{~cm}-1$. That band shifted towards higher wavenumbers to around $3400 \mathrm{~cm}-1$ in other samples what might be attributed to an increase in the interlayer $\mathrm{O}-\mathrm{OH}$ distance (Somasundaran, 2006) as a result of leaching of the vermiculite base materials and different structure of the hydrotalcite like samples. Another band, present in the spectra of all the samples associated with water vibrations was detected at around $1640 \mathrm{~cm}-1$ (Chukanov, 2014). The band corresponding to the stretching vibration of Al2OH in vermiculite at $3326 \mathrm{~cm}-1$ (Madejová and Komadel, 2001) was present in the spectra of the S-samples and the hybrid materials, however it was not detected in the L-samples. The materials obtained from the solid fraction after treatment in 3.2 M acid (W-S-3.2 and Ve-S-3.2) did not show a band at around $3555 \mathrm{~cm}-1$ attributed to Fe2OH or AlFeOH vibrations (Besson and Drits, 1997; Parikh et al., 2014) suggesting strong leaching of the octahedral sheets in more concentrated acid.

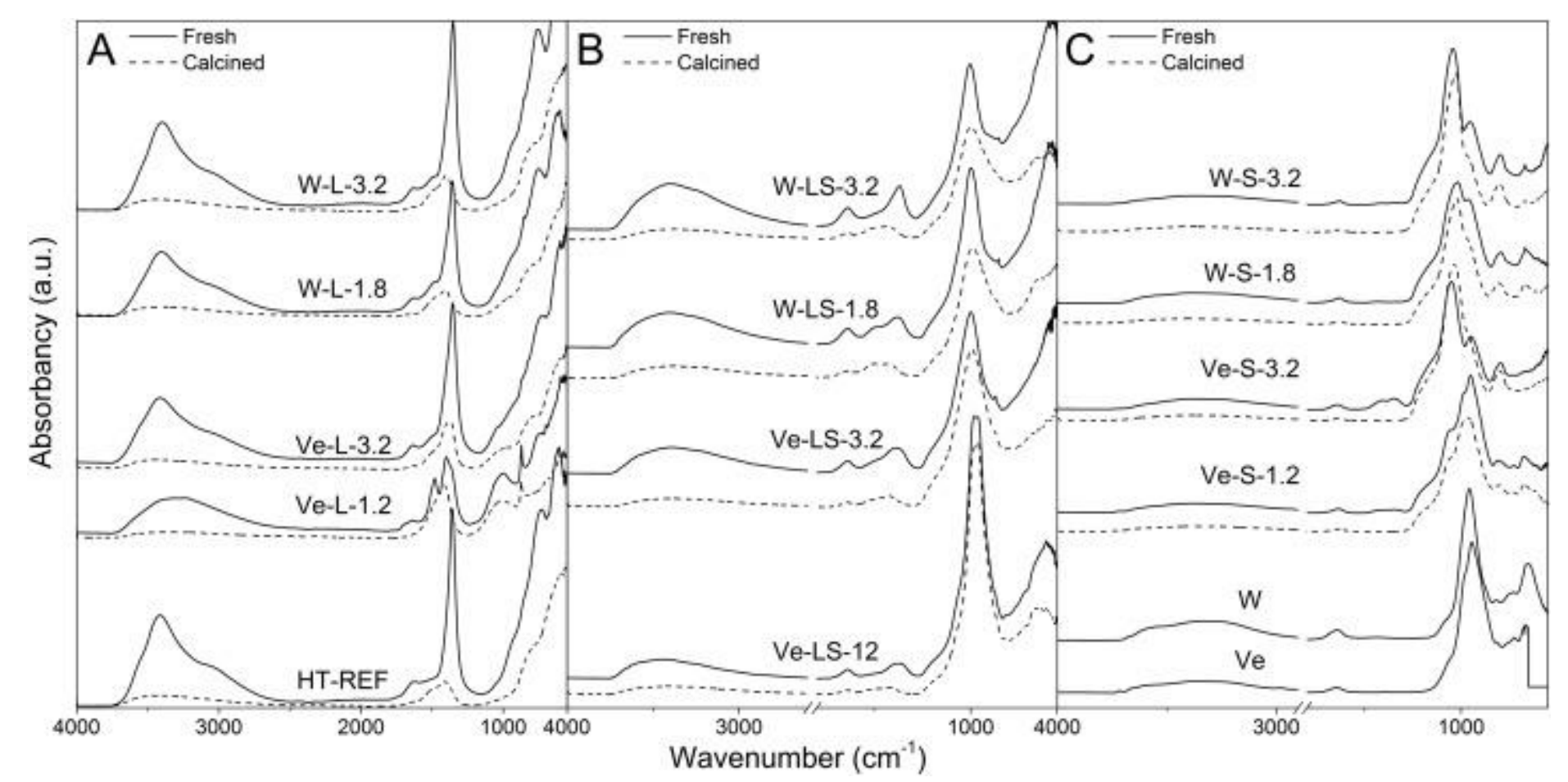

Fig. 6. ATR spectra of the material obtained from the liquid phase after acid treatment of vermiculites (A), hybrid vermiculitehydrotalcite adsorbents from the liquid and solid phase $(B)$, and the solid phase remained after the acid treatment $(C)$.

The band at around $3030 \mathrm{~cm}-1$ assigned to CO3-H2O (Kloprogge and Frost, 2006) or solvation water molecules highly condensed in micropores (Kuśtrowski et al., 2004) was present in the spectrum of the reference hydrotalcite and each L-sample. Two bands at $1750 \mathrm{~cm}-1$ and $1480 \mathrm{~cm}-1$ were detected in the spectra of the samples containing the LDH and are associated with NO3- anions (Kloprogge and Frost, 2006). Interlayer carbonate gave a band at around $1360 \mathrm{~cm}-1$ (Kloprogge et al., 2004; Kloprogge and Frost, 2006) with high intensity in the case of the L-samples. That peak was not observed in the starting vermiculites and S-samples, however where both solid and liquid fractions were used for the synthesis that band had moderate intensity. Other bands associated with carbonate species were found in the range between 1500 and $1400 \mathrm{~cm}-1$ (El Gaini et al., 2009; Santos et al., 2013).

The S-samples gave a band at around $1200 \mathrm{~cm}-1$ attributed to SiO stretching in amorphous silica (Chmielarz et al., 2012; Barabaszová and Valášková, 2013). In the spectra of the hybrids that reflection was less intense, and it was not observed in the reference hydrotalcite and the L-samples.

The starting vermiculites exhibited a sharp band at $955 \mathrm{~cm}-1$ ascribed to SiO stretching in the clay mineral layer (Stubičan and Roy, 1961; Madejova, 2003; Ritz et al., 2014). It was present as a shoulder on the bands at $1045 \mathrm{~cm}-1$ and $1020 \mathrm{~cm}-1$ assigned to amorphous silica (Chmielarz et al., 2012; Barabaszová and Valášková, 2013) in the case of S-samples with an exception of the sample Ve-S-1.2 where the band at around $955 \mathrm{~cm}-1$ remained almost the same. Those results suggest intensive transformation of the vermiculites after acid treatment and stronger resistance to such modification of the expanded mineral. In the spectra of the hybrid samples the SiO vibration was manifested by a band at around $1000 \mathrm{~cm}-1$ (Stubičan and Roy, 1961; Ritz et al., 2014) without a shoulder at $955 \mathrm{~cm}-1$. Both starting vermiculites showed in their spectra a band at $650 \mathrm{~cm}-1$ assigned to SiO bending (Stubičan and Roy, 1961; Madejová and Komadel, 2001), which was no longer present in the spectra of the S-samples where the band at $670 \mathrm{~cm}-1$ appeared together with the 
band at around $800 \mathrm{~cm}-1$ assigned to amorphous silica (Madejova, 2003). The $670 \mathrm{~cm}-1$ band was also detected in the samples produced with liquid and solid phase wastes (LS).

The reference hydrotalcite and the L-samples showed a band at $860 \mathrm{~cm}-1$ assigned to $\mathrm{Fe}-\mathrm{OH}$ vibrations (Ovejero et al., 2013), at $940 \mathrm{~cm}-1$ assigned to $\mathrm{FeO}-\mathrm{OH}$ vibrations (Qwabe et al., 2015), and at $745 \mathrm{~cm}-1$ assigned to a translational mode of M-OH moieties (Sobhana et al., 2016). The band present in their spectra at around $610 \mathrm{~cm}-1$ did not appear in the hybrid materials. Every sample, except those from the solid residue, and the raw materials, gave a band at around $850 \mathrm{~cm}-1$ suggesting formation of AlFeOH units (Madejová and Komadel, 2001).

Each material containing LDH showed bands in the range of $600-550 \mathrm{~cm}-1$ associated with stretching and bending vibrations of M-O, M-O-M, and O-M-O bonds (Madejova, 2003; Nakamoto, 2009) and hydroxyl group associated mainly with Al, which were influenced by probably one $\mathrm{Mg}$ in its coordination environment (Kloprogge and Frost, 2006).

After calcination no significant changes of the ATR spectra were observed. However, all the bands in the range of higher wavenumbers associated with $\mathrm{OH}$ groups vibrations appeared with reduced intensity. The intensity of the band related to the vibration of CO32- was also lowered in samples containing LDH.

\subsection{Batch adsorption experiments}

The results of batch adsorption experiments for the dyestuffs AR, CR, R and copper cations onto fresh and calcined samples are gathered in Table 1 and are discussed below.

\begin{tabular}{|c|c|c|c|c|c|c|c|c|}
\hline \multirow[t]{3}{*}{ Sample } & \multicolumn{8}{|c|}{ Adsorption capacity $\left(\mathrm{mgg}^{-1}\right)$} \\
\hline & \multicolumn{4}{|l|}{ FRESH } & \multicolumn{4}{|c|}{ CALCINED } \\
\hline & AR & CR & $\mathbf{R}$ & $\mathrm{Cu}^{2+}$ & AR & CR & $\mathbf{R}$ & $\mathrm{Cu}^{2+}$ \\
\hline $\mathrm{Ve}$ & $27.2 \pm 0.7$ & $5 \pm 2$ & $6 \pm 2$ & $19 \pm 1$ & $21.0 \pm 0.5$ & $4 \pm 1$ & $1 \pm 1$ & $17 \pm 3$ \\
\hline Ve-S-1.2 & $31 \pm 2$ & $1.02 \pm 0.03$ & $48.2 \pm 0.4$ & $7 \pm 1$ & $33.6 \pm 0.6$ & $34 \pm 2$ & $1.3 \pm 0.4$ & $22 \pm 1$ \\
\hline Ve-LS-1.2 & $18 \pm 1$ & $43 \pm 1$ & $22.6 \pm 0.6$ & $35 \pm 1$ & $36 \pm 1$ & $84 \pm 1$ & $14 \pm 1$ & $62 \pm 3$ \\
\hline Ve-L-1.2 & $5 \pm 2$ & $39.7 \pm 0.7$ & $26 \pm 1$ & $40.7 \pm 0.6$ & $33 \pm 1$ & $155 \pm 3$ & $92 \pm 1$ & $49.5 \pm 0.8$ \\
\hline Ve-S-3.2 & $26 \pm 2$ & $4 \pm 2$ & $49.0 \pm 0.4$ & $3.2 \pm 0.7$ & $29 \pm 1$ & $51 \pm 3$ & $1.1 \pm 0.1$ & $26.6 \pm 0.7$ \\
\hline Ve-LS-3.2 & $17 \pm 2$ & $36.3 \pm 0.4$ & $25.9 \pm 0.1$ & $38.1 \pm 0.5$ & $43 \pm 2$ & $75.3 \pm 0.5$ & $34.1 \pm 0.5$ & $75 \pm 1$ \\
\hline Ve-L-3.2 & $3.8 \pm 0.6$ & $37 \pm 2$ & $77.5 \pm 0.5$ & $51 \pm 1$ & $35.9 \pm 0.7$ & $214 \pm 2$ & $119.5 \pm 0.3$ & $66 \pm 3$ \\
\hline $\mathrm{W}$ & $48.5 \pm 0.6$ & $7 \pm 1$ & $8 \pm 3$ & $19 \pm 2$ & $48.4 \pm 0.5$ & $9 \pm 3$ & $9 \pm 4$ & $17 \pm 2$ \\
\hline W-S-1.8 & $76 \pm 1$ & $4.7 \pm 0.2$ & $47 \pm 2$ & $9 \pm 1$ & $73 \pm 2$ & $34 \pm 2$ & $0.44 \pm 0.02$ & $15 \pm 1$ \\
\hline W-LS-1.8 & $15.7 \pm 0.3$ & $41.1 \pm 0.5$ & $29 \pm 2$ & $37 \pm 1$ & $38.1 \pm 0.9$ & $219 \pm 1$ & $110 \pm 2$ & $70 \pm 1$ \\
\hline W-L-1.8 & $2.4 \pm 0.4$ & $39.7 \pm 0.4$ & $58.4 \pm 0.5$ & $48 \pm 3$ & $38.2 \pm 0.6$ & $158 \pm 2$ & $137 \pm 2$ & $60 \pm 3$ \\
\hline W-S-3.2 & $35.1 \pm 0.2$ & $7 \pm 1$ & $47.8 \pm 0.7$ & $2.4 \pm 0.8$ & $31 \pm 2$ & $36 \pm 3$ & $1.11 \pm 0.01$ & $15 \pm 2$ \\
\hline W-LS-3.2 & $15.62 \pm 0.03$ & $42.3 \pm 0.9$ & $61 \pm 1$ & $35 \pm 1$ & $44 \pm 1$ & $238 \pm 3$ & $111 \pm 2$ & $72 \pm 3$ \\
\hline W-L-3.2 & $0.9 \pm 0.2$ & $41.6 \pm 0.4$ & $96.0 \pm 0.4$ & $44 \pm 3$ & $35.4 \pm 0.5$ & $289 \pm 3$ & $109 \pm 1$ & $64 \pm 2$ \\
\hline HT-REF & $0.63 \pm 0.06$ & $40 \pm 2$ & $75 \pm 2$ & $31 \pm 3$ & $35.6 \pm 0.6$ & $297 \pm 3$ & $125 \pm 1$ & $61.2 \pm 0.7$ \\
\hline
\end{tabular}

Table 1. Results of the batch adsorption experiments of AR, CR, R and Cu2+ onto the fresh and calcined samples. 
3.2.1. Adsorption on the starting and acid leached materials (S-samples)

Both starting vermiculites exhibited moderate, not affected by calcination, adsorption properties for the cationic dye AR and copper cations, while the removal of the anionic dyes CR and R was negligible. In the S-samples the capacity for Cu2+ decreased, compared to the starting materials, proportionally to the acid concentration used in the treatment. However, upon the thermal treatment the adsorption capacities returned to the level of the starting materials. AR was removed more efficiently on the samples obtained after the treatment with less concentrated acid. The capacities deceased after exceeding the optimal acid concentration, which is in accordance with the literature (Forgacs et al., 2004; Stawiński et al., 2017a). The removal of $\mathrm{R}$ increased after the treatment and was not influenced by acid concentration. Calcination of these samples resulted in a drastic decrease in the capacity for that dye. No significant changes were observed in the adsorption capacity for CR between $\mathrm{W}$ and $\mathrm{Ve}$ and the uncalcined samples, however calcination of the S-samples significantly increased their capacities.

\subsubsection{Adsorption on the materials obtained from liquid fraction (L-samples)}

These adsorbents exhibited good adsorption capacity for the anionic dyes and copper ions. Adsorption of AR on them and on the reference hydrotalcite (HT-REF) was insignificant, however the thermal treatment enabled them to adsorb that dye. The adsorption levels for CR were comparable to the reference material and similar for all the uncalcined samples. However, the capacities were significantly enhanced after calcination, with more distinctive increase for the samples treated in more concentrated acid. The capacities for $\mathrm{R}$ increased after treatment in more concentrated acid, however, contrarily to the adsorption of $\mathrm{CR}$, after calcination the change was more pronounced when less concentrated acid was used in the treatment. Moreover, the sample W-L-1.8 exceeded the capacity of the reference hydrotalcite. Regarding removal of $\mathrm{Cu} 2+$ every sample obtained from that fraction had higher capacity than the reference material. No statistically significant difference was observed between the materials obtained from W however, for the adsorbents derived from Ve, the sample Ve-L-3.2 reached higher adsorption level than Ve-L-1.2. The thermal treatment increased the capacity for Cu2+ of each material.

\subsubsection{Adsorption on the hybrid materials (LS)}

The hybrids exhibited intermediate adsorption properties between the S- and L-samples and were able to remove both anionic and cationic dyes, and copper ions. The capacity for AR was higher than the capacity of samples L, and lower than of samples $S$, and it increased after calcination. For $C R$ and $R$ the adsorption capacities were lower than those of the samples $L$, nonetheless significantly higher than those of the samples $S$. Regarding adsorption of $R$ the materials obtained from $W$ reached higher capacities than their counterparts formed from $\mathrm{Ve}$, and in both cases the treatment in $3.2 \mathrm{M}$ acid gave better properties. However, for adsorption of CR no significant differences were observed between the samples. Calcination highly increased the capacities for CR of all the samples. Regarding adsorption of $\mathrm{R}$ an increase in the capacities was observed in the samples derived from W and Ve-LS-3.2 while for the sample Ve-LS-1.2 the capacity decreased. Regardless the starting material, all the materials had similar adsorption capacity for Cu2+ that increased around two times after calcination.

\subsubsection{Insights to the adsorption mechanism}

Acid activation of vermiculite increases their adsorption capacity for cationic dyes, with a certain optimal acid concentration giving the best results. The biggest increase was in the adsorbents obtained from $\mathrm{W}$ treated with $1.8 \mathrm{M}$ acid where the capacity changed from $48.5 \pm 0.6$ to $76 \pm 11 \mathrm{mg} \mathrm{g}-1$. This is attributed to leaching of the octahedral sheets, delamination of the structure, development of porosity and formation of an amorphous silica phase. The changes provide new adsorption centers (surface hydroxyl groups) and make those already existing more accessible. Moreover, a decrease in the layer charge, thus cation exchange capacity (CEC), facilitate migration of dye molecules in between the layers (Maqueda et al., 2009; Steudel et al., 2009; Stawiński et al., 2017c). Regarding adsorption of metal cations, the lowering of CEC resulted in decreased adsorption capacity for that adsorbate. Nonetheless, it was reported that nitric acid up to concentration $0.05 \mathrm{M}$ can be used to treat vermiculite without a loss in the adsorption capacity (Stawiński et al., 2017c). Moreover, calcination of such materials results in regeneration of the capacity for metal cations without any significant changes in the capacity regarding cationic dyes. The thermal modification of clays changes their composition, structure and adsorption ability (Stefanova, 2001). One of the changes is lowering of CEC due to migration of cations into the layer structure, where they become basically non-exchangeable, which facilitates penetration of other species into the interlayer space (Anastas and Warner, 1998). The 
other one is related to structural changes due to formation of an amorphous phase (Peters and lberg, 1978). The decrease in the XRD 002 reflection of vermiculite in the samples derived from $\mathrm{W}$ suggests formation of the amorphous phase, however the temperature used during treatment was not high enough to affect the starting martial, thus no changes in its capacity for Cu2+ was observed. The expanded material had been subjected to a thermal treatment in the process of exfoliation, thus treatment at $450{ }^{\circ} \mathrm{C}$ did not produce any structural changes in the case of the samples Ve and Ve-S-1.2. However, activation in stronger acid rendered the material more susceptible to further thermal modifications, thus the capacity of the samples Ve-S-3.2 increased. Also the amorphous silica was dehydroxylated at temperature around $350^{\circ} \mathrm{C}$ what created new adsorption centers for metal cations. However, thermal treatment greatly influenced the adsorption properties of some of the materials towards anionic dyes and copper cations. The biggest change regarding $\mathrm{CR}$ was in the sample W-L-3.2 where the capacity changed from $41.5 \mathrm{mg} \mathrm{g}-1$ to $289 \mathrm{mg} \mathrm{g}-1$ followed by W-LS-3.2 with a change from $42.3 \pm 0.9$ to $238 \pm 3 \mathrm{mg} \mathrm{g}-1$. Regarding adsorption of $\mathrm{R}$, the biggest change was in the sample W-LS-1.8 and W-L-1.8 with an increase from $29 \pm 2$ to $219 \pm 1 \mathrm{mg} \mathrm{g}-1$ and from $58.4 \pm 0.8$ to $158 \pm 2 \mathrm{mg} \mathrm{g}-1$, respectively. In the case of Cu2+ the change was the most prominent in the samples W-LS-3.2 and Ve-LS-3.2 with almost similar increase of about $37 \mathrm{mg} \mathrm{g}-1$ reaching an average level of $73.5 \mathrm{mg} \mathrm{g}-1$. In the case of LDH bearing materials the hydrotalcite-like phase was transformed in mixed oxides after calcination. That material has an unique property and is able to reconstruct the LDH structure when in contact with water, and incorporate between the layers anions available in the solution (Stawiński et al., 2017b). In that case removal of dyes was more efficient since there was no need to exchange the interlayer species impeding diffusion into the interlayer gallery. Hydrotalcite-like materials despite their positive layer charge are also able to adsorb metal cations. The positive charge of the layers attracts hydroxide ions around the surfaces of LDH crystals in aqueous solution and metal hydroxides are formed. Furthermore, the carbonates that are unavoidably present in the interlayer space and attached to the surface can come into contact with metal cations and form insoluble carbonates (Barnabas et al., 2016).

\subsubsection{Synergic effect on adsorption}

Based on comparison of adsorption capacities of hypothetical adsorbents prepared by mixing ex-situ of both fractions used in the synthesis in adequate proportions, with the capacities of the hybrids obtained during the experiment, a strong synergic effect on the adsorption was noticed. It was the strongest on the adsorption of CR and R onto the sample Ve-LS-1.2 where the adsorption increased by 400 and $300 \%$, respectively. The effect was not observed in adsorption of AR onto the sample Ve-LS-3.2, and for the remaining samples the capacity for that dye was diminished reaching only $34 \%$ on W-LS-1.8. The value was also below $100 \%$ for the adsorption of $\mathrm{R}$ onto the samples derived from $\mathrm{W}$ and $105 \%$ for the sample Ve-LS-3.2. Adsorption of Cu2+ was enhanced up to $168 \%$. After calcination that effect was also the most visible in adsorption of CR, however onto the sample W-LS-1.8 with an increase by $339 \%$. Moreover, the situation in the case of adsorption of $\mathrm{R}$ reversed and on the samples derived from $\mathrm{W}$ showed strong synergic effect, on the level of 196 and $179 \%$ for the lower and the higher acid concentration, respectively, and those derived from Ve reached values below $100 \%$. Adsorption of AR onto all samples was enhanced up to $135 \%$, and an increase by 176 to $214 \%$ was observed in the case of $\mathrm{Cu} 2+$.

Here again, lower crystallinity degree and dispersion of LDH or oxide phase on porous silica support, are beneficial for adsorption results. On one hand, reconstruction of small crystals proceeds faster, on the other hand, different adsorption centers located at the edges are more numerous and more available (e.g. to form inner- and outer sphere complexes) (Peters and lberg, 1978).

\section{Conclusions}

Waste by-products of acid activation of expanded (Ve) and raw vermiculite (W) can be used as a substrate for synthesis of hydrotalcitelike structure adsorbents (LDH). Their adsorption capacities depended on the starting material and the acid concentration used in the activation, and generally the materials were more efficient in removing anionic dyes (Congo Red - CR, and Reactive Red - R) and copper cations than the cationic dye Astrazon Red - AR. The highest removals were obtained after calcination at $450{ }^{\circ} \mathrm{C}$ on the adsorbents formed from W treated in $3.2 \mathrm{M} \mathrm{HNO} 3$ for $\mathrm{CR}$ and Cu2+ reaching $289 \pm 3$ and $64 \pm 2 \mathrm{mg} \mathrm{g}-1$, respectively, and on its counterpart obtained in $1.8 \mathrm{M} \mathrm{HNO} 3$ for $\mathrm{AR}$ and $\mathrm{R}$ with $38.2 \pm 0.6$ and $137 \pm 2 \mathrm{mg} \mathrm{g}-1$, respectively. While for the corresponding ones derived from $\mathrm{Ve}$, the removal attained $214 \pm 2$ and $66 \pm 3 \mathrm{mg} \mathrm{g}-1$ for $\mathrm{CR}$ and Cu2+, respectively, and $35.9 \pm 0.7$ and $119.5 \pm 0.3 \mathrm{mg} \mathrm{g}-1$ for $A R$ and $R$, respectively. 
Moreover, the waste by-product was combined with the acid activated vermiculite to form hybrid composite materials. These adsorbents exhibited good adsorption properties, that were also increased by calcination, for cationic and anionic species. The calcined hybrids obtained after the treatment in 3.2 M HNO3 derived from both vermiculites exhibited similar adsorption capacities for AR and Cu2+ ( $43 \pm 2$ and $44 \pm 1 \mathrm{mg} \mathrm{g}-1$ for $A R$, and $75 \pm 1$ and $72 \pm 3 \mathrm{mg} \mathrm{g}-1$ for Cu2+, respectively on $\mathrm{Ve}$ and $\mathrm{W}$ ), however the ones originated from W had better removal levels of $C R$ and $R$ than their counterparts formed from Ve $(75.3 \pm 0.5$ and $238 \pm 3 \mathrm{mg} g-1$, for $C R$, and $34.1 \pm 0.5$ and $111 \pm 2 \mathrm{mg} \mathrm{g}-1$ for $\mathrm{R}$, respectively on Ve and $\mathrm{W}$ ). Furthermore, a strong synergic effect on the adsorption was observed in the hybrid adsorbents that removed more pollutants than the theoretical materials obtained by mixing ex situ acid activated vermiculite and the waste-originating LDH. The effect occurred in all the samples but it was stronger in the ones derived from Ve, where the capacity reached up to $400 \%$ of the theoretical one on the sample Ve-LS-1.2.

The proposed synthesis stands as a solution for the problem of waste generation during acid activation of clay minerals. Moreover, hybrid materials can be useful in pollution control where the composition of wastewater is complex. Furthermore, the synthesis does not produce any hazardous waste, neither requires toxic substrates/reagents to their manufacturing, nor high temperatures or pressures are needed in the process, fulfilling the principles of Green Chemistry.

\section{Acknowledgements}

This work, within the scope of the project of Labóratorio Associado para Química Verde - Technologia e Processos Limpos UID/QUI/50006, is financed by national founds of FCT/MEC and co-financed by Fundos FEDER (POCI-01-0145-FEDER-007265) within the scope of the partnership agreement PT2020. Part of the research was carried out with the equipment purchased thanks to the financial support of the European Regional Development Fund in the framework of the Polish Innovation Economy Operational Program (contract no. POIG.02.01.00-12-023/08). To all financing sources the authors are greatly indebted.

\section{References}

Ali, I., Asim, M., Khan, T.A., 2012. Low cost adsorbents for the removal of organic pol-lutants from wastewater. J. Environ. Manag. 113, 170-183.

Anastas, P.T., Warner, J.C., 1998. Green Chemistry: Theory and Practice. OxfordUniversity Press.

Angın, D., Köse, T.E., Selengil, U., 2013. Production and characterization of activatedcarbon prepared from safflower seed cake biochar and its ability to absorb reactivedyestuff. Appl. Surf. Sci. 280, 705-710.Ayranci, E., Duman, O., 2009. In-situ UV-visible spectroscopic study on the adsorption ofsome dyes onto activated carbon cloth. Sep. Sci. Technol. 44, 3735-3752.

Ayranci, E., Duman, O., 2010. Structural effects on the interactions of benzene andnaphthalene sulfonates with activated carbon cloth during adsorption from aqueoussolutions. Chem. Eng. J. 156, 70-76.

Barabaszová, K.Č., Valášková, M., 2013. Characterization of vermiculite particles afterdifferent milling techniques. Powder Technol. 239, 277-283.

Barnabas, M.J., Parambadath, S., Mathew, A., Park, S.S., Vinu, A., Ha, C.-S., 2016. Highlyefficient and selective adsorption of In3+on pristine Zn/Al layered double hydroxide(Zn/Al-LDH) from aqueous solutions. J. Solid State Chem. 233, 133-142.

Bergaya, F., Lagaly, G., 2006. General introduction: clays, clay minerals, and clay science.In: Bergaya, F., Theng, B.K.G., Lagaly, G. (Eds.), Handbook of Clay Science. ElsevierLtd..

Besson, G., Drits, V.A., 1997. Refined relationships between chemical composition ofdioctahedralfine-grained mica minerals and their infrared spectra within the ohstretching region. Part I: identification of the $\mathrm{OH}$ stretching bands. Clay and ClayMinerals 45, 158-169.

Bhatnagar, A., Jain, A.K., 2005. A comparative adsorption study with different industrialwastes as adsorbents for the removal of cationic dyes from water. J. Colloid InterfaceSci. 281, 49-55.

Braterman, P.S., Xu, Z.P., Yarberry, F., 2004. Layered double Hydroxides (LDHs). In:Auerbach, S.M., Carrado, K.A., Dutta, P.K. (Eds.), Handbook of Layered Materials.Marcel Dekker, U.S.A..Chmielarz, L., Wojciechowska, M., Rutkowska, M., Adamski, A., Węgrzyn, A., 
Kowalczyk,A., Dudek, B., Boroń, P., Michalik, M., Matusiewicz, A., 2012. Acid-activated ver-miculites as catalysts of the DeNOxprocess. Catal. Today 191, 25-31.

Chukanov, N.V., 2014. Infrared Spectra of Mineral Species. (Extended library).

Duman, O., Ayranci, E., 2010. Attachment of benzo-crown ethers onto activated carboncloth to enhance the removal of chromium, cobalt and nickel ions from aqueoussolutions by adsorption. J. Hazard. Mater. 176, 231-238.

Duman, O., Tunç, S., 2008. Electrokinetic properties of vermiculite and expanded ver-miculite: effects of pH, clay concentration and mono- and multivalent electrolytes.Sep. Sci. Technol. 43, 3755-3776.

Duman, O., Tunç, S., Gürkan Polat, T., 2015a. Adsorptive removal of triarylmethane dye(basic red 9) from aqueous solution by sepiolite as effective and low-cost adsorbent.Microporous Mesoporous Mater. 210, 176-184.

Duman, O., Tunç, S., Polat, T.G., 2015b. Determination of adsorptive properties of ex-panded vermiculite for the removal of C. I. Basic Red 9 from aqueous solution: ki-netic, isotherm and thermodynamic studies. Appl. Clay Sci. 109-110, $22-32$.

Duman, O., Tunç, S., Bozoğlan, B.K., Polat, T.G., 2016. Removal of triphenylmethane andreactive azo dyes from aqueous solution by magnetic carbon nanotube-k-carra-geenan-Fe3O4 nanocomposite. J. Alloys Compd. 687, 370-383.

El Gaini, L., Lakraimi, M., Sebbar, E., Meghea, A., Bakasse, M., 2009. Removal of indigocarmine dye from water to Mg-Al-CO3-calcined layered double hydroxides. J.Hazard. Mater. 161, 627-632.

Forgacs, E., Cserháti, T., Oros, G., 2004. Removal of synthetic dyes from wastewaters: areview. Environ. Int. 30, 953-971.

Hansen, B., Koch, H.C., Bender, C., 1995. Synthesis and characterization of pyroaurite.Appl. Clay Sci. 10, 5-19.

Kloprogge, J.T., Frost, R.L., 2006. In: Rives, V. (Ed.), Infrrared and Raman SpectorscopicStudies of Layered Double Hydroxides (LDHs). Layered Double Hydroxides: Presentand Furure. Nova Science Publishers, pp. 153-215.

Kloprogge, J.T., Hickey, L., Frost, R.L., 2004. FT-Raman and FT-IR spectroscopic study ofsynthetic Mg/Zn/Al-hydrotalcites. J. Raman Spectrosc. 35.

Komadel, P., Madejova, J., 2006. Acid activation of clay minerals. In: Bergaya, F., Theng,B.K.G., Lagaly, G. (Eds.), Handbook of Clay Science. Elsevier Ltd..

Kuśtrowski, P., Chmielarz, L., Bożek, E., Sawalha, M., Roessner, F., 2004. Acidity andbasicity of hydrotalcite derived mixed Mg-Al oxides studied by test reaction of MBOHconversion and temperature programmed desorption of NH3and CO2. Mater. Res.Bull. 39, 263-281.Lagaly, G., Ogava, M., Dekany, I., 2006. Clay mineral organic interactions. In: Bergaya, F., Theng, B.K.G., Lagaly, G. (Eds.), Handbook of Clay Science. Elsevier Ltd..

Leitão, A., Serrão, R., 2005. Adsorption of phenolic compounds from water on activatedcarbon: prediction of multicomponent equilibrium isotherms using single-componentdata. Adsorption 11, 167-179.

Mejova, J., 2003. FTIR techniques in clay mineral studies. Vib. Spectrosc. 31, 1-10.

Mejová, J., Komadel, P., 2001. Baseline studies of the clay minerals society sourceclays: infrared methods. Clay Clay Miner. 49, 410432.Maqueda, C., Perez-Rodriguez, J.L.,Šubrt, J., Murafa, N., 2009. Study of ground andunground leached vermiculite. Appl. Clay Sci. $44,178-184$

Nakamoto, K., 2009. Infrared and Raman Spectra of Inorganic and CoordinationCompounds, Part A, Theory and Applications in Inorganic Chemistry, 6th Edition.Wiley, New Jersey.

Ovejero, G., Rodríguez, A., Vallet, A., García, J., 2013. Ni/Fe-supported over hydro-talcites precursors as catalysts for clean and selective oxidation of Basic Yellow 11 :reaction intermediates determination. Chemosphere 90, 1379-1386.

Parikh, S.J., Goyne, K.W., Margenot, A.J., Mukome, F.N.D., Calderón, F.J., 2014. Chapterone - soil chemical insights provided through vibrational spectroscopy. In: Donald,L.S. (Ed.), Advances in Agronomy. Academic Press, pp. 1-148.

Pereira, L., Alves, M., 2011. Dyes-environmental impact and remediation. In: Malik, A.,Grohmann, E. (Eds.), Environmental Protection Strategies for SustainableDevelopment. Springer Science \& Business Media.

Peters, T., lberg, R., 1978. Mineralogical changes duringfiring od calcium-rich clays. Am.Ceram. Soc. Bull. 5, 503-509. 
Pinnavaia, T.J., 2004. Foreword. In: Auerbach, S.M., Carrado, K.A., Dutta, P.K. (Eds.),Handbook of Layered Materials. Marcel Dekker, U.S.A..

Qwabe, L.Q

., Friedrich, H.B., Singh, S., 2015. Preferential oxidation of CO in a hydrogenrich feed stream using Co-Fe mixed metal oxide catalysts prepared from hydrotalciteprecursors. J. Mol. Catal. A Chem. 404-405, 167-177.Ritz, M., Zdrálková, J., Valášková, M., 2014. Vibrational spectroscopy of acid treatedvermiculites. Vib. Spectrosc. 70, 63-69.

Roy, A., Forano, C., Besse, J.P., 2006. In: Rives, V. (Ed.), Layered Double Hydroxides:Synthesis and Post-Synthesis Modification. Layered Double Hydroxides: Present and Future Nova Science Publishers, Inc., New York.

Rozada, F., Calvo, L.F., García, A.I., Martín-Villacorta, J., Otero, M., 2003. Dye adsorptionby sewage sludge-based activated carbons in batch andfixed-bed systems. Bioresour.Technol. 87, 221-230.

Rozov, K., Berner, U., Taviot-Gueho, C., Leroux, F., Renaudin, G., Kulik, D., Diamond,L.W., 2010. Synthesis and characterization of the LDH hydrotalcite-pyroaurite solid-solution series. Cem. Concr. Res. 40, 1248-1254.

Santos,R.M.M., Gonçalves, R.G.L., Constantino, V.R.L., da Costa, L.M., da Silva, L.H.M.,Tronto, J., Pinto, F.G., 2013. Removal of Acid Green 68:1 from aqueous solutions bycalcined and uncalcined layered double hydroxides. Appl. Clay Sci. 80-81, 189-195.

Sevekow, U., 2003. Health and safety aspects. in: Hunger, K. (Ed.). Indystrial Dyes.Chemistry, Properties, Applications. Wiley-Vch, Weinheim.

Sobhana, L.S.S., Mehedi, R., Malmivirta, M., Paturi, P., Lastusaari, M., Dîrtu, M.M.,Garcia, Y., Fardim, P., 2016. Heteronuclear nanoparticles supported hydrotalcitescontaining $\mathrm{Ni}(\mathrm{II})$ and $\mathrm{Fe}(\mathrm{III})$ stable photocatalysts for Orange II degradation. Appl.Clay Sci. 132$133,641-649$.

Somasundaran, P., 2006. Encyclopedia of Surface and Colloid Science. Taylor \& Francis.

Stawiński, W., Freitas, O., Chmielarz, L., Węgrzyn, A., Komędera, K., Błachowski, A.,Figueiredo, S., 2016. The influence of acid treatments over vermiculite based mate-rial as adsorbent for cationic textile dyestuffs. Chemosphere 153, 115-129.

Stawiński, W., Węgrzyn, A., Dańko, T., Freitas, O., Figueiredo, S., Chmielarz, L., 2017a.Acid-base treated vermiculite as high performance adsorbent: insights into the me-chanism of cationic dyes adsorption, regeneration, recyclability and stability studies.Chemosphere 173, 107-115.

Stawiński, W., Węgrzyn, A., Freitas, O., Chmielarz, L., Figueiredo, S., 2017b. Dual-func-tion hydrotalcite-derived adsorbents with sulfur storage properties: dyes and hy-drotalcite fate in adsorption-regeneration cycles. Microporous Mesoporous Mater.250, $72-87$.

Stawiński, W., Węgrzyn, A., Freitas, O., Chmielarz, L., Mordarski, G., Figueiredo, S.,2017c. Simultaneous removal of dyes and metal cations using an acid, acid-base andbase modified vermiculite as a sustainable and recyclable adsorbent. Sci. TotalEnviron. 576, 398408.

Stefanova, R.Y., 2001. Metal Removal by Thermally Activated Clay Marl. Journal ofEnvironmental Science and Health. Part A. 36(3). Toxic/hazardous substances \&environmental engineering, pp. 293-306.

Steudel, A., Batenburg, L.F., Fischer, H.R., Weidler, P.G., Emmerich, K., 2009. Alterationof swelling clay minerals by acid activation. Appl. Clay Sci. 44, 105-115.

Stubičan, V., Roy, R., 1961. Infrared spectra of layer-structure silicates. J. Am. Ceram.Soc. 44, 625-627.

Ummartyotin, S., Pechyen, C., 2016. Strategies for development and implementation ofbio-based materials as effective renewable resources of energy: a comprehensivereviewon adsorbent technology. Renew. Sust.Energ. Rev. 62, 654-664.

Węgrzyn, A., Stawiński, W., Freitas, O., Komędera, K., Błachowski, A., Jęczmionek,Ł.,Dańko, T., Mordarski, G., Figueiredo, S., 2018. Study of adsorptive materials obtainedby wetfine milling and acid activation of vermiculite. Appl. Clay Sci. 155, 37-49. 